\title{
Interactive comment on "Very high-resolution terrain surveys of the Chã das Caldeiras lava fields (Fogo Island, Cape Verde)" by Gonçalo Vieira et al.
}

\author{
Bianca Wagner (Referee) \\ bwagner1@gwdg.de \\ Received and published: 26 January 2021
}

The comment was uploaded in the form of a supplement:

https://essd.copernicus.org/preprints/essd-2020-289/essd-2020-289-RC2-

supplement.pdf

Interactive comment on Earth Syst. Sci. Data Discuss., https://doi.org/10.5194/essd-2020-289, 2020. 